\title{
FEATURE
}

\section{So you need a social monitoring plan: Now what?}

\author{
Tricia G. Knoot, GL Drake Larsen, and Lisa A. Schulte
}

S

oil and water conservation personnel have a long tradition of collaborating and learning directly from the constituencies with whom they work. Collaborative, cooperative, and participatory arrangements between agencies, organizations, and stakeholders have been described as essential to effectively address ecosystem management goals. In the last two decades, collaborative efforts among managers and stakeholders have become more formal in character and have been defined as "adaptive comanagement" (Armitage et al.2009). The adaptive comanagement approach allows for flexibility and responsiveness to new and emerging social and ecological issues, while paying particular attention to the diverse and dynamic interests of natural resource stakeholders (Pahl-Wostl 2006; Pahl-Wostl et al. 2007; Atwell et al. 2010). A core value of this approach is enhancing the capacity of all stakeholders (e.g., farmers, conservation organizations, and government agencies) to reflect on management outcomes and adapt to meet project goals and expectations. Fulfilling this core value necessitates a structured approach to monitoring and evaluation (Plummer and Armitage 2007; Armitage et al. 2009), which can offer insights into effectiveness of various participatory approaches and encourages experimentation and adjustments that can address an individual project as well as an organization's strategies (Chess et al. 2000; Low and Randhir 2005).

Most soil and water conservation program managers and program participants recognize the need for monitoring and evaluation, but this has often been addressed in the ecological realm (Stem et al. 2005), such as the collection and analy-

Tricia G. Knoot is a research social scientist with the Wisconsin Department of Natural Resources, Wildife and Forestry Research Section, Madison, Wisconsin. GL Drake Larsen is the communications and policy associate with Practical Farmers of lowa, Ames, lowa. Lisa A. Schulte is an associate professor in the Department of Natural Resource Ecology and Management, lowa State University, Ames, lowa. sis of weather, water quality, soil quality, fish population, and wildlife population data. However, in situations where ecological and social indicators are intricately related, such as farmer maintenance of conservation practices and water quality, assessing social conditions through a monitoring approach is crucial (Wagner 2005; Genskow and Prokopy 2011). The information gained through such an approach can help to assess the perspectives of participants related to the current program's goals, functions (e.g., staff and participant relationships), and various activities (e.g., workshops and technical assistance). For example, it can inform how to most effectively manage relationships between program participants and managers, alert to and allow adaptation to minor problems, identify new opportunities for maintaining program participation, and detect incremental changes (or the lack thereof) in identified outcomes of interest (e.g., participant awareness, knowledge, and behaviors) (Genskow and Prokopy 2010). In other words, developing a social monitoring plan provides program managers and leaders timely and relevant information to best address constituents' concerns and enhance learning by participants, program managers, and partners.

A social monitoring evaluation plan that focuses on outcomes and actively involves the users of the data can also help managers and partners look to the future by (1) gaining an understanding of current motivators or constraints to participation, which can be used to improve future program design that attracts new participants and impacts ecological outcomes at broader spatial scales; (2) evaluating, comparing, and contrasting current achievements and preferred targets for project outcomes as determined by the partners to improve partners' decision making regarding future projects; and (3) providing accountability to funding agencies regarding how money is used and the ability of a project to achieve intended outcomes, with the potential to generate information to justify allocation of future program support.
Once convinced a social monitoring plan is needed, where is the best place to start? There are a variety of approaches to evaluation, including assessing program goals, processes, outputs, and/or outcomes (Taylor-Powell et al. 1996; Stufflebeam 2001; Patton 2002). The field of (social) program evaluation provides a rich foundation of theory and social science methods that, when focusing on a particular program (also termed an "intervention") of interest, helps address the question of whether the program is effective at achieving the target goals. The techniques for collecting data to address this question can take many forms (e.g., mailed surveys, qualitative interviews, and group events) and can occur at various points throughout a program (Plummer et al. 2007; Dillman et al. 2008). The specific approach described below is introductory and provides elements of an adaptive approach to learn about a program. For detailed and comprehensive description of a monitoring process designed to address nonpoint source pollution management, see The Social Indicators Planning and Evaluation System (Genskow and Prokopy 2011). Regardless of the evaluation approach or method used, systematic steps are needed to provide the most reliable and useful information (Taylor-Powell et al. 1996; Patton 2000).

The following is a simple guide that can be used to initiate a basic social monitoring plan. This approach is designed to encourage active involvement from those who will use its findings. Farmers are used in the example of the Fishers and Farmers Partnership below, but graziers, landowners, or visitors could be substituted for farmers based on the target audience.

\section{STEP 1: IDENTIFY THE INTENDED USE OF THE EVALUATION}

A user-based approach, termed "utilization-focused evaluation," provides an opportunity to gain information that is most needed by managers and partners for timely decision making, and increases the likelihood that the evaluation findings will be both relevant and appli- 
cable (Patton 2000; Stufflebeam 2001). Consequently, the steps in the evaluation are to be directly conducted, interpreted, and adapted over time by the users of the evaluations (e.g., managers and program partners). It is important that managers and partners first work together to identify their intended use of evaluation findings. In the case of one group we have worked with, the Fishers and Farmers Partnership for the Upper Mississippi River Basin (www.fishersandfarmers.org/), the evaluation was developed to help partners gain an understanding of farmer needs and successful participation, information which can be used to attract new participants and improve ecological outcomes at broader spatial scales.

\section{STEP 2: ISOLATE OUTCOMES OF GREATEST INTEREST AND USE}

Outcomes of greatest interest for project managers and partners can often be derived from organizational mission statements or strategic plans. For the example case of the Fishers and Farmers Partnership, the mission is "... to support locally led projects that add value to farms while restoring aquatic habitat and native fish populations." Given this goal, measureable social outcomes of interest are likely to include facilitating farmer learning, enhancing local engagement, and encouraging participant satisfaction.

\section{STEP 3: DETERMINE INDICATORS/ MEASURES THAT ARE ASSOCIATED WITH EACH OF THE IDENTIFIED OUTCOMES}

Continuing with the Fishers and Farmers Partnership example, indicators of learning can include measuring changes in participant awareness, knowledge, and technical skills. Additionally, understanding participants' preferred methods for receiving new information can help program managers tailor education programs. Engagement is a broad outcome of interest, which could to be reflected by measures of farmers' perceived ability and motivation to maintain the project, farmers' motivation to connect with conservation professionals, and farmers' likelihood to recommend the project to other farmers. Sharing of experiences with other farmers may take different forms, where farmers may reach out to others to share experiences, successes, and challenges. Other farmers may also contact a farmer to learn more about an observed practice. Of note, the likelihood to recommend a project to others may be a critical indicator-previous consumer-related research found that this factor was most indicative of continued engagement (Plummer et al. 2007). Satisfaction may be measured by assessing farmers' perspectives on the expertise that they have received, perceived costs versus benefits gained through their participation in the projects, and project flexibility.

\section{STEP 4: IDENTIFY APPROPRIATE METHODS OF DATA COLLECTION}

A variety of quantitative and qualitative techniques can be utilized in the collection of social monitoring and program evaluation data (Patton 2002; Dillman et al. 2008). People can be surveyed in person or by phone, in a large group format (such as focus group or field day discussion), via the Internet, or through paper questionnaires. Each technique is suited to address different goals and can also be used in combination as a mixed-methods approach (Dillman et al. 2008). A simple technique that can meet the need for an outcomes-based evaluation is the paper questionnaire. The survey can be administered once the project is in place and at a specified time following project completion to identify changes in learning and perceived opportunities or barriers to involvement.

Additional complementary data can be collected through other techniques — such as qualitative in-depth interviews, focus groups, or observation-if deemed necessary for addressing future goals. Such qualitative methods can provide insights that may be difficult to identify through a structured survey (Prokopy 2011). These methods can be used to cross-check survey results and provide a greater level of confidence in interpretations and findings. For example, qualitative methods can add detail and depth to interpreting quantitative data and can also capture and communicate important stories. These methods also require more time and technical expertise, however, and thus it is important to clearly identify the need for these methods before pursing them (Patton 2002). In the case of the Fishers and Farmers Partnership example, we developed questions that could be easily and efficiently delivered through a quantitative survey by direct mail or email communications with a farmer. However, the open-ended questions could also be used to collect detailed stories through indepth interviews with farmers.

\section{STEP 5: CREATE THE SURVEY INSTRUMENT}

The process of creating a survey instrument includes identifying broad information to be gathered by the survey, developing individual evaluative questions that can provide the needed information, determining the structure of questions, and ensuring clarity and simplicity through careful choice of words and phrases (Dillman et al. 2008). Key information needs could be captured with the following questions:

- What opportunities/constraints contribute to participant decisions to engage with a program or project?

- What/how do participants gain value from the projects?

- Do projects decrease or complement profitability?

- Do projects increase knowledge of the overall program and program goals?

- Do initial projects develop the skills needed to carry out further projects?

- Are participants satisfied with their experience with the program and/or projects, and with the benefits gained?

- Is the value gained from the projects perceived as worth the costs to participants?

- Are the projects perceived as fitting local conditions and regional needs?

- Are participants willing/interested in engaging with other participants and recommending projects to others?

- Are participants willing to maintain and upkeep projects?

Examples of survey questions that capture information to address many of these questions are provided in table 1. The survey questions are structured to primarily elicit quantitative measures of learning, engagement, and satisfaction; however, survey questions should be pretested to determine if the questions are reliable and valid at addressing the indicators of interest. Several open-ended questions can also 


\section{Table 1}

An example evaluation framework, highlighting the linkages between anticipated project outcomes, potential questions in the survey instrument, and suggested ways to analyze and interpret the measures. The Fishers and Farmers Partnership is used in this example.

\begin{tabular}{|c|c|}
\hline Anticipated outcomes & Survey questions \\
\hline \multirow[t]{3}{*}{ Learning } & $\begin{array}{l}\text { Describe your level of understanding of the following topics before and at } \\
\text { present on a } 1 \text { to } 5 \text { scale (very little to very deep understanding): } \\
\text { the partnership, a watershed, how to connect with your neighbors. }\end{array}$ \\
\hline & $\begin{array}{l}\text { What is your preferred form/method of receiving new or updated inform } \\
\text { tion? In-person, email or internet, mailings. }\end{array}$ \\
\hline & $\begin{array}{l}\text { Please provide your opinion on the following statements about agriculture } \\
\text { and fish habitat on a scale from } 1 \text { to } 5 \text { (strongly disagree to strongly } \\
\text { agree): farmland should be managed with the interests of water quality } \\
\text { and fish habitat; activities that take place on farms can have an impact on } \\
\text { water quality and fish; farmland owners should have to consider the interest } \\
\text { of water quality and fish habitat when making land management decisions. }\end{array}$ \\
\hline Engagement & $\begin{array}{l}\text { Please rate the importance of each possible issue for your decision to plan and } \\
\text { manage land for water quality and fish habitat on your farm on a scale } \\
\text { from } 1 \text { to } 5 \text { (not at all important to very important): meets personal recreation } \\
\text { goals; protect nature and biological diversity; access economic incentive } \\
\text { programs; access specialists for technical help; gain knowledge of whole farm. }\end{array}$ \\
\hline
\end{tabular}

What do you like most about the program? What do you like least about the program?

The program's mission is to.... The following statements are related to how you feel projects on your land have, or have not, met this mission on a scale from 1 to 5 (strongly disagree to strongly agree): projects have improved on-farm productivity; on-farm profitability; the longterm sustainability of your farm; on-farm fish and wildlife habitat; personal enjoyment of the land; other (please describe).

Please provide your opinion on the following statements about the program and related projects on a scale from 1 to 5 (strongly disagree to strongly agree): I would recommend the program to other local landowners and farmers; I have access to the financial resources needed to maintain and upkeep projects on my land into the future; I have access to the technical resources needed to maintain and upkeep projects on my land into the future; I will continue to maintain and upkeep projects on my land into the future.

Satisfaction Please rate the importance of each possible issue for your decision to plan and manage land for water quality and fish habitat on your farm on a scale from 1 to 5 (not at all important to very important): meet personal recreation goals; protect nature and biological diversity; access economic incentive programs; access specialists for technical help; gain knowledge about your whole farm.

What do you like most about the program? What do you like least about the program?

What suggestions do you have to improve the program's support for projects such as yours?

In what other ways has the program benefited you? In what other ways has the program cost you?

Please provide your opinion on the following statements about the program and related projects on a scale from 1 to 5 (strongly disagree to strongly agree): the program offers an appropriate amount of flexibility; the program provides appropriate expertise for my needs; the overall value that I gain from the project on my land is worth the cost; I am satisfied with my experience with the program.

\section{Analysis and interpretation}

To assess learning, the user would subtract the participant's level of understanding "before" from their level of understanding "currently" to identify a change.

Identifies the participant's preference for receiving information, which can help project managers adjust and plan future information delivery.

Provides various measures of awareness and knowledge related to the program and its goals.

Opportunities and concerns relate to the values that participants have for their land and the projects. These values have the potential to influence likelihood to maintain and upkeep the project and recommend the practice to others.

Findings from these open-ended questions can contribute to the interpretation of engagement.

Identifies aspects of the project that influence the value of a farm. Findings can help interpret engagement and can be used to assess whether the value added by the project aligns with existing values.

Provides indicators for measuring engagement, including their willingness to recommend and capacity to maintain the projects.

Opportunities and concerns have the potential to influence participant satisfaction.

Findings from these open-ended questions can contribute to the interpretation of satisfaction.

Allows participants to share any improvements that they see are needed in order to ensure satisfaction.

Additions or reductions in value will contribute positively or negatively, respectively, to satisfaction.

Provides indicators of satisfaction related to perceived flexibility, expertise, and cost/benefit. 
be included to collect responses that provide further understanding through the words chosen by participants. Examples of open-ended questions may include the following: What do you like most (or least) about participating in the program? What suggestions do you have for improvements to our program to support projects such as yours? Please describe in your own words the characteristics of a successful project.

Because monitoring and evaluation is often carried out by project managers and partners, survey instruments need to be flexible and allow for modification over time to meet new goals or changing ecological (e.g., type of fish habitat in greatest need for restoration, new or changing levels of pollutants, or extreme events such as droughts or floods) and social conditions (e.g., demographics, values, and needs of landowners) and insights gained through previous surveys. For example, responses from questions posed in an initial survey (e.g., improvements needed to a program) can contribute to the design of a structured question in subsequent surveys that could assess the relative importance of these particular responses.

\section{STEP 6: DELIVER THE QUESTIONNAIRE}

A systematic protocol for survey deployment is recommended to ensure adequate response rates for the paper survey (Dillman et al. 2008). We suggest a modified version of the widely used Tailored Design Method, which includes the creation of an introductory/cover letter (figure 1). The cover letter must adequately explain the purpose and importance of the survey, ensure participant confidentiality, and adequately thank the respondents for their participation. Follow-up mailings, or additional contact, are then needed to ensure proper response (Dillman et al. 2008). The recommended follow-up schedule includes the following steps:

- Within one week after the initial mailing all participants are sent a reminder and thank you postcard. The post card indicates appreciation to those who have already responded and reminds others to complete and return the questionnaire soon.

- Two to four weeks after initial mailing all nonrespondents are sent a

\section{Figure 1}

Basic template for a letter to be sent to survey participants along with questionnaire.

[Professional letterhead]

Date

Dear [Participant]:

Due to your participation in the [title] project, we are asking for your help to identify ways in which we can improve our program and provide exceptional assistance to project participants. Your participation in this survey is voluntary, and the information you provide will be kept confidential. We expect this survey to take up to 15 minutes of your time.

If you have any questions, please feel free to contact me at [contact information]. Thank you very much for your help!

Yours truly,

[Signed in blue ink]

reminder letter along with a full replacement survey.

- A week after the full replacement survey is delivered all nonrespondents are contacted by phone or mailed a new letter (considered "special contact") to encourage completion of the survey. In the case when projects receive a limited response, a follow-up with those nonrespondents to understand how they may differ from respondents can help identify if a nonresponse bias may be of concern.

Additional tactics can be used to improve response rates, such as financial or nonmonetary incentives, notification of the survey through a pre-notice letter, personalization of survey materials (e.g., personally sign each letter), and delivery by First Class or Certified Mail (Dillman et al. 2008).

\section{STEP 7: ANALYZE AND INTERPRET RESULTS}

The focus on an outcomes-based evaluation framework offers the opportunity to provide an understanding of the changes that have resulted from project activities and specifically answer the following questions: What has changed? How do these changes relate to project activities and your overall mission? What improvements could be made? The ultimate focus of analysis and interpretation should be defined by project managers and/or partners; however, at a minimum, outcomes should be expressed through descriptive statistics for a single project. This is achieved by averaging overall evaluative questions/indicators that are applicable and related to each outcome. For example, it may be advantageous to report on learning in general, in addition to reporting on each particular indicator of learning that was measured. The range of responses to a particular question across respondents may also be included to describe variation in the population. Finally, frequency distributions can be used to describe the number of participants (and percentage of participants) who responded similarly to a question. All of these calculations can be handled quite easily with standard spreadsheet software, such as Microsoft Excel. Note that it is only applicable to average across questions if the questions use the same measurement format and consistently address a similar indicator.

Some reflection by project managers and other partners is also required in order to gain a more comprehensive understanding of the factors contributing to change and to better identify potential improvements. Table 2 presents a set of reflection questions for project managers and partners. A focus on both analysis and reflection provides additional opportunities for learning and adaptation within each project.

\section{STEP 8: SHARE}

Insights gained through social monitoring and evaluation can be shared in a variety of ways with project participants, managers, and partners, e.g., through inperson contact, newsletters, and/or group events. Ultimately, encouraging participant engagement requires continued invest- 


\section{Table 2}

\section{Reflection questions for project managers to assist with the interpretation of findings.}

\section{Open-ended questions \\ In what ways do project participants primarily view success and how does their definition of suc- cess align with the intended outcomes that you envisioned for the project? \\ What activities have you conducted that promote learning (e.g., delivery of material, number of interactions with participants, and interaction settings)? \\ Describe ways in which you observed participants to be learning (e.g., gaining knowledge, skills, and awareness). \\ What worked well in your interactions with participants? \\ What were challenges (e.g., delays in project implementation, technical hurdles, miscommunica- tion, and misunderstanding by participants) that you encountered in working with participants or carrying out the project? \\ In what ways do you feel these challenges may have impacted participant engagement or satisfac- tion with the project, and what evidences suggests so? \\ What resources do you feel are needed to help improve the learning process, enhance engage- ment, or improve satisfaction?}

ment by project managers and partners in their bond with participants and fosters relationships among participants in a way that stimulates learning, the creation of meaning, and a shared identity (create a "community of practice" [Wenger 1998]). Developing a community of practice can involve group events, such as workshops or field days, which promote sharing of interests and experiences. Project managers can help facilitate these group events, while also affording an opportunity for online discussion or individual contact among participants (e.g., email lists, discussion boards, and phone lists).

\section{CONCLUSIONS}

The adaptive comanagement of our natural resources requires that soil and water conservation personnel are flexible and responsive to new and emerging social and ecological issues. The development of a social monitoring plan in concert with an ecological monitoring plan can provide a powerful foundation as projects get off the ground, offering a sound baseline from which social and ecological measures can be compared over time. For project managers or program partners, instituting a social monitoring plan will help with recognition of the diverse and dynamic interests of natural resource stakeholders. The systematic approach to social monitoring outlined here has been adapted from standardized and vetted social survey protocol and program evaluation tools. This eight- step process emphasizes timely, flexible, and practical feedback that can enhance the ability to adapt and adjust to the needs and values of participants, hopefully helping all to embrace learning and adaptation.

\section{ACKNOWLEDGEMENTS}

We thank the Fishers and Farmers Partnership, through the Iowa Soybean Association, for funding and feedback on the project that lead to this paper. We also appreciate support by the Wisconsin Department of Natural Resources, Bureau of Science Services, during the final revisions of the manuscript, and Matthew Mitro, fisheries research scientist, Madison, Wisconsin, for manuscript review and recommendations.

\section{REFERENCES}

Armitage, D.R., R. Plummer, F. Berkes, R.I. Arthur, A.T. Charles, I.J. Davidson-Hunt, A.P. Diduck, N.C. Doubleday, D.S. Johnson, M. Marschke, P. McConney, E.W. Pinkerton, and E.K.Wollenberg. 2009. Adaptive co-management for social-ecological complexity. Frontiers in Ecology and the Environment 7(2):95-102.

Atwell, R.C., L.A. Schulte, and L.M. Westphal. 2010. How to build multifunctional agricultural landscapes in the US Corn Belt: Add perennials and partnerships. Land Use Policy 27(4):1082-1090.

Chess, C., B.J. Hance, and G. Gibson. 2000. Adaptive participation in watershed management. Journal of Soil and Water Conservation 55(3):248-252.

Dillman, D., Smyth, J., and Christain, L. 2008. Internet, Mail, and Mixed-Mode Surveys: The Tailored Design Method. 3rd Edition. Hoboken, NJ:Wiley. Genskow, K., and L.S. Prokopy. 2010. Lessons learned in developing social indicators for regional water quality management. Society and Natural Resources 23(1):83-91.

Genskow, K., and L. Prokopy (eds.). 2011. The Social Indicator Planning and Evaluation System (SIPES) for Nonpoint Source Management: A Handbook for Watershed Projects. 3rd Edition. Great Lakes Regional Water Program. http://35.8.121.111/ si/Info/pdfs/SI_Handbook_v4_02012012.pdf.

Low, S., and T. Randhir. 2005. Watershed management, structural characteristics, information processing, and cooperative strategies in conservation organizations. Journal of Soil and Water Conservation 60(6):281-287.

Pahl-Wostl, C. 2006. The importance of social learning in restoring the multifunctionality of rivers and floodplains. Ecology and Society 11(1):10.

Pahl-Wostl, C., M. Craps, A. Dewulf, E. Mostert, D. Tabara, and T. Taillieu. 2007. Social learning and water resources management. Ecology and Society $12(2): 5$.

Patton, M.Q. 2000. Utilization-focused Evaluation. In Evaluation Models, D.L. Stufflebeam, G.F. Madaus, and T. Kellaghan, eds., 425-438. Boston, MA: Kluwer.

Patton, M.Q. 2002. Qualitative Research and Evaluation Methods. Thousand Oaks, CA: Sage.

Plummer, R., and D. Armitage. 2007. A resiliencebased framework for evaluating adaptive co-management: Linking ecology, economics and society in a complex world. Ecological Economics 61:62-74.

Plummer, J., B. Cook, D. Diforio, B. Schachter, I. Sokolyanskaya, and T. Korde. 2007. Measures of Engagement, Volume II. New York: Advertising Research Foundation. http://www.classmatandread. net/class/2.Measures $\% 20$ of $\% 20$ Engagement.pdf.

Prokopy, L.S. 2011. Agricultural human dimensions research: The role of qualitative research methods. Journal of Soil and Water Conservation 66(1):9A-12A, doi:10.2489/jswc.66.1.9A.

Stem, C., R. Margoluis, N. Salafsky, and M. Brown. 2005. Monitoring and evaluation in conservation: A review of trends and approaches. Conservation Biology 19(2):295-309.

Stufflebeam, D. 2001. Evaluation models. New Directions for Evaluation 89:7-98.

Taylor-Powell, S. Steele, and M. Douglah. 1996. G3658-1, Program Development and Evaluation: Planning a Program Evaluation. Madison, WI: University of Wisconsin-Extension.

Wagner, M.M. 2005. Watershed-scale social assessment. Journal of Soil and Water Conservation 60(4):177-186.

Wenger, E. 1998. Communities of Practice: Learning, Meaning, and Identity. Cambridge, UK: Cambridge University Press. 